\title{
High Performance Work Practices and Work Results on Non-Profit Institutions
}

\author{
Margot LIATIRA NIKOLAOU ${ }^{\mathrm{a}}$, Charalampos PLATIS ${ }^{\mathrm{b}, 1}$, Emmanouil ZOULIAS ${ }^{\mathrm{c}}$ and \\ Panagiotis GOREZIS ${ }^{\mathrm{d}}$ \\ a Psychologist (MSc) - Psychotherapist, Athens, Greece \\ ${ }^{\mathrm{b}}$ CEO, KETEKNY (Greek DRG Institute), Athens, Greece \\ ${ }^{\mathrm{c}}$ Health Informatics Laboratory, Faculty of Nursing, National and Kapodistrian \\ University of Athens, Athens, Greece \\ ${ }^{\mathrm{d}}$ School of Economics, Faculty of Economics and Political Sciences, Aristotle \\ University, Thessaloniki, Greece
}

\begin{abstract}
High Performance Work Practices (HPWP) has not been sufficiently investigated in the frame of Non-profit Organizations. At the same time the need of NPOs for satisfied employees keeps rising, because of the increased demand for their services, especially in the health care sector. The purpose of this thesis is to investigate the relationship between HPWP and the mediation of Work Passion. The survey was based on a quantitative methodological approach, with the use of questionnaires, and the sample was constituted of 125 employees of health and mental health Non-profit Organizations based in Athens. The statistical analysis was implemented with the use of IBM SPSS Statistics 20. It was shown that HPWP are positively related to Work Passion. The implementation of HighPerformance Work Practices and the recruitment of employees who share common values with the organization can contribute significantly in this direction, since they are related to higher career satisfaction, through the increase of employee's work passion.
\end{abstract}

Keywords. Non-profit Organizations, High Performance Work Practices, Career Satisfaction, Work Passion, Person-Organization Fit.

\section{Introduction}

High Performance Work Practices is a term that can be seen in the literature also as High-Performance Work Systems or High Involvement Work Practices or High Commitment Work Systems [1]-[3]. The term has received also, various definitions, such as "A set of separate but interconnected Human Resource Management Strategy (HRMS) practices, which concern the recruitment, selection, development, mobilization and retention of employees" [4]. Another more descriptive definition is as sets of mutually complementary HRMS policies and practices, which promote rigorous employee selection practices, increased career opportunities and development of skills, as well as the use of performance-based incentives, team-based work practices and participatory [5]. As a result, the above-mentioned definitions, a key element of HPWP

1 Corresponding Author, Charalambos Platis, CEO, KETEKNY (Greek DRG Institute), Athens, Greece; E-mail: chplatis@gmail.com. 
is their reference and study, as a "total" or "pack" of practices and not as individual, autonomous practices since it has become apparent that their results, when used as a whole, are more significant than those from the sum of the individual results practices. In addition to that, it is obvious that their results, when used as a whole, are more significant than those we would take in case of sum the individual results by the included practices [6]-[8].

\section{Methods}

The study of the literature in relation to the methodology used in the research of the HPWP and the passion for work showed, with great clarity, that the appropriate research method is that of completing questionnaires by the employees of an organizations, a method which was followed within this work.

The research sample used consists of 125 employees of non-profit organizations, who are active in the field of health and mental health and are work in Athens. It is important to mention that all the selected organizations had a legal status of Non-Profit Association, Civil Non-Profit Company, Non-Governmental Organization. They are also private law entities while social cooperatives were excluded, as they fall under a different legal framework. The employees were of various specialties and levels and had a legal, salaried employment relationship with each institution. The volunteers, the executives of the Administration and the Human Resources department of the organization were excluded from the research. The research took place from November 2016 to February 2017. An informative letter sent to the address of ten non-profit health and mental health organizations, informing about the purposes of the research, and asking for permission to send questionnaires, in electronic form.

In the present study all measurements were made using the five-point Likert scale, where the value $1=$ Strongly Disagree and the value $5=$ Strongly Agree. The questionnaire used is a combination of two existing questionnaires concerning the two main variables of the research, these are also free to use according to their licence in the literature. The combined questionnaire was tested for reliability using Cronbach's Alpha coefficient, which exceeds 0.70 . This value is highly reliable according to Nunnally, Bernstein and Berge (1967) [9]. As a result, the questions that make up each variable of the questionnaire are highly correlated, and we can use to extract a total sum using the sums of the individual questions with high reliability. High Performance Work Practices were measured using twelve items from the scale of Takeuchi [10]. This scale examines practices that fall into different categories such as training, evaluation, teamwork, participation in decision making and staff selection. Examples include: "Management always listens to the opinion and ideas of the team before making any decision", "Performance appraisal is based on objective, measurable results", "The selection of employees focuses on the selection of the best candidate, regardless of the respective job". Passion for Work was measured using the scale created by Vallerand [11], which consists of six elements, such as "I am passionate about my job", "My job allows me to live unforgettable experiences", "My work harmonizes with the other activities of my life". 


\section{Results}

In the total of 125 participants women were $70.2 \%$ and men to $29.8 \%$, while the average age of the sample was 35 years. Married responders were $36.3 \%, 32.3 \%$ in a relationship and $28.2 \%$ with no relationship. In terms of educational level, the largest percentage were graduates of higher education, Higher Education $(48.4 \%)$ or holders of a postgraduate diploma $(40.3 \%)$. In addition to that, $55 \%$ of the participants were health or mental health professionals and performed clinical duties in the organization, $28.2 \%$ held managerial positions and $16.1 \%$ seemed to fall into the broader category of general duties employees. Finally, the average number of years of work in the same organization was 6.06 years, while the average number of years of holding the specific job in the specific organization was 4.65 years.

The reliability of the measuring instruments was checked using Cronbach's Alpha coefficient. This is a factor that checks how reliable each factor is, by measuring the internal consistency of the variables, and takes values from 0 to 1 . As shown in Table 1 , the Cornbach's Alpha coefficient is high enough for all variables, since it exceeds 0.7 , the minimum value that a variable must take to be considered reliable, according to Nunnally [12]. This fact shows that the questions that make up each variable are highly interrelated, and we can, with reliability, extract a total sum from the sums of the individual questions and use it.

Table 1. Reliability Indicator Cronbach's Alpha

\begin{tabular}{ccc}
\hline Variable & Cronbach's Alpha & No. of Questions \\
\hline HPWP & 0.92 & 12 \\
Passion for Work & 0.87 & 6 \\
\hline
\end{tabular}

\subsection{Descriptive Statistics}

In relation to the statistical descriptive data of the demographic data, as mentioned above, $70 \%$ of the total sample were women and the average age was 35 years. Marital status appeared to be almost equally distributed, with married life slightly higher, at $36.3 \%$, compared to the answer "in a relationship" (32.3\%) and "free" $(28.2 \%)$, while in a very large percentage of $88 \%$ the participants had university education or hold a postgraduate diploma $40.3 \%$. More than half of the respondents $(55 \%)$ were health or mental health professionals and exercised clinical duties, with an average of 6.06 years of work in the organization and an average of 4.65 years of holding the specific job in the organization.

Going to the descriptive data of the variables, they are found in Table 2, which shows the Mean and Standard Deviation for each of them. Observing the Averages and given that all the measurement scales were five-point, it becomes clear that the sample shows a high degree of passion for the work, with an average of almost 4 . The lowest average is shown by the HPWP, which move very close to the answer "I neither agree nor disagree" (average $=3.27$ ), which indicates that the average of the respondents do not clearly understand whether the organization, in which they work, applies HPWP or do not want to take a position on this issue. Finally, the Standard Deviations seem to be moving at low levels $<1$, since the variables start from 0.76 which is the Standard Deviation of the passion for work while the HPWP with 0.93. This fact of low prices shows that the answers of the participants tend to be close to the average and are not scattered in a wider range of prices. 
Table 2. Average and Standard Deviation

\begin{tabular}{ccc}
\hline Variable & Average & Standard Deviation \\
\hline HPWP & 3.27 & 0.93 \\
Passion for Work & 3.92 & 0.76 \\
\hline
\end{tabular}

\subsection{Correlation among Demographics and Variables}

The Pearson correlation coefficient was used to investigate the correlation between demographic factors and research variables. The specific coefficient, which takes values -1 to +1 allows us to check the form of correlation of the variables (positive or negative correlation), as well as the level of statistical significance $p$, the intensity of the correlation (statistically significant correlation when $\mathrm{p}<0.05$ and strong statistically significant correlation when $p<0.01$ ). As can be seen in Table 3, HPWP is positively correlated with passion for work $(\mathrm{r}=0.57, \mathrm{p}<0.01)$.

Table 3. Pearson Factor

\begin{tabular}{ccccccccc}
\hline Variable & $\mathbf{1}$ & $\mathbf{2}$ & $\mathbf{3}$ & $\mathbf{4}$ & $\mathbf{5}$ & $\mathbf{6}$ & $\mathbf{7}$ & $\mathbf{8}$ \\
\hline Gender & & & & & & & & \\
Age & -0.08 & & & & & & & \\
Marital Status & 0.05 & -0.05 & & & & & & \\
Educational Level & 0.00 & -0.03 & $-0.20^{*}$ & & & & & \\
Years in Organization & 0.04 & $0.67^{* *}$ & $-0.20^{*}$ & $-0.18^{*}$ & & & & \\
Year in same position & 0.03 & $0.58^{* *}$ & $-0.20^{*}$ & -0.16 & $0.76^{* *}$ & & & \\
Position type & -0.10 & -0.08 & 0.07 & -0.16 & -0.14 & -0.14 & & \\
HPWP & -0.06 & 0.08 & 0.01 & -0.04 & -0.03 & -0.04 & 0.10 & \\
passion for work & -0.05 & -0.00 & 0.08 & 0.07 & -0.11 & 0.04 & 0.07 & $0.57^{* *}$ \\
\hline$* \mathrm{p}<0.05, * * \mathrm{p}<0.01$ & & & & & & &
\end{tabular}

\subsection{Regression Analysis}

The Regression Analysis that carried out in this research with HPWP function as an independent variable and the passion for work takes on the role of the dependent. The results reveal the positive influence of HPWP on the passion for work $(\mathrm{B}=0.49 . \mathrm{P}<$ 0.01 ) confirming our Hypothesis. The results of the Regression Analysis presented in Table 4.

Table 4. Regression Analysis

\begin{tabular}{lccc}
\hline & B & R-sq & P \\
\hline HPWP $(\mathrm{X})$ and Passion for Work (Y) & 0.49 & 0.37 & 0.00 \\
\hline
\end{tabular}

\section{Discussion}

According to the results presented appeared that HPWP positively affects the passion for work. This work is the first that proves this relationship. The same is true as far as the second case, the one of attitudes and behaviours, which are influenced by employees' passion for their work. Expanding this field and responding to the need to explore new variables that are influenced by a passion for work [13].

Another finding of this work is that when the employee feels that he is working in an organization with which he/she shares common values, then the HPWP applied, lead to the development of a passion for work to a higher degree. This finding is quite close to the recent research of Kooij and Boon [14]. This research is subject, like any study, 
to limitations, despite the important findings. We should point out the limitation of data collected by NGOs based in a single city, Athens in Greece. Therefore, the generalization of its results must be done, in any case, carefully.

\section{Conclusions}

The research findings make it clear that the managements or Human Resources executives of non-profit organizations should use High Performance Work Practices, be interested in whether their employees are satisfied with their career and know that they are. It is important to select employees who share common values and philosophy with those of the organization. Obviously, human resource management cannot focus only on specific points, as there are a number of factors that must be taken into account in order to select, operate and support employees in such a way that the organization can perform to the maximum. So beyond the specific and important findings of the present study, perhaps its greatest contribution is the encouragement for more study, at a theoretical level and more engagement, at the level of administrations, with the human resources of the third sector of the economy and especially those involved with sensitive area of health and mental health services.

\section{References}

[1] Chuang E, Dill J, Morgan J, Konrad T. A configurational approach to the relationship between HighPerformance Work Practices and frontline health care workers outcomes. Health Services Research. 2012;47(4):1460-1481.

[2] Posthuma R, Campion M, Masimova M, Campion M. A High Performance Work Practices taxonomy: Integrating the literature and directing future research. Journal of Management. 2013;39:1184.

[3] Mihail D, Kloutsiniotis P. The effects of high-performance work systems on hospital employees' workrelated well-being: Evidence from Greece. European Management Journal. 2016;34(4):424-438.

[4] Zacharatos A, Barling J, Iverson R. High-Performance Work Systems and occupational safety. Journal of Applied Psychology. 2005;1(1):77-93.

[5] Godard J, Delaney J. Reflections on the high performance paradigm's implications for industrial relations as a field. Industrial and Labor Relations Review. 2000;53(3):482-502.

[6] Gittel J, Seidner R, Wimbush J. A relational model of how high performance work systems work. Articles in Advance. 2009:1-17.

[7] Boxall P, Macky K. Research and theory on High-Performance Work Systems: Progressing the highinvolvement stream. Human Resource Management Journal. 2009;19(1):3-23.

[8] Jiang K, Lepak D, Han K, Hong Y, Kim A, Winkler A. Clarifying the construct of human resource systems: Relating human resource management to employee performance. Human Resource Management Review. 2012;22:73-85.

[9] Nunnally C, Bernstein H, Berge T. Psychometric Theory (Vol. 226). New York, NY: McGrawHill; 1967.

[10] Takeuchi R, Lepak D, Wang H, Takeuchi K. An empirical examination of the mechanisms mediating between high performance work systems and the performance of Japanese organizations. Journal of Applied Psychology. 2007;92(4):1069-1083.

[11] Vallerand J, Houlfort N. Passion at work: Toward a new conceptualization. In: Gilliland W, Steiner DD and Skarlicki DP (eds) Emerging Perspectives on Values in Organizations. Greenwich Village. CT: Information Age Publishing. 2003;175-204.

[12] Nunnally JC. This Week's Citation Classic. Psychometric theory. 1979;1978.

[13] Perrewé P. Developing a passion for work passion: Future directions on an emerging construct. Journal of Organizational Behavior. 2014;(1):145-150.

[14] Kooij D, Boon C. Perceptions of HR practices, person - organisation fit, and affective commitment: The moderating role of career stage. Human Resource Management Journal. 2017;1-15. 